\title{
Repercussões do autismo no subsistema fraterno na perspectiva de irmãos adultos
}

\author{
Impacts of autism in the fraternal \\ subsystem from adult \\ siblings' perspective
}

\author{
Pâmela Kurtz CEZAR ${ }^{1}$ \\ Luciane Najar SMEHA ${ }^{2}$
}

\begin{abstract}
Resumo
O autismo é um quadro clínico de início precoce que compromete o processo de desenvolvimento humano, especialmente nos âmbitos da comunicação e da socialização. Desse modo, o objetivo principal deste estudo foi compreender as repercussões de ter um irmão com autismo na trajetória de vida de sujeitos adultos. Para tanto, realizou-se uma pesquisa qualitativa com delineamento exploratório e transversal. A coleta de dados compreendeu entrevistas semiestruturadas realizadas individualmente com quatro participantes adultos que têm irmãos autistas. Os resultados indicaram que a relação fraterna foi afetada em decorrência do transtorno austístico, influenciando nas escolhas pessoais e modos de ser dos participantes, além de exigir-lhes uma rotina de cuidados diferenciada que se estende ao longo da vida. Conclui-se que os irmãos de autistas precisam de suporte para enfrentar essa vivência. Assim, a Psicologia pode auxiliar na ampliação da rede de apoio às famílias, em especial na escuta desses irmãos.
\end{abstract}

Palavras-chave: Relações entre irmãos; Relações familiares; Transtorno autístico.

\begin{abstract}
Autism is a clinical condition with early onset that compromises the process of human development, especially in communication and socialization areas. Therefore, the main objective of this study was to understand the impacts of having an autistic sibling on the life course of adult subjects. A qualitative exploratory research with a transversal design was carried out. Data were collected through semi-structured interviews conducted individually with four adults with autistic siblings. The results indicated that the fraternal relationship was affected by having a sibling with autism, influencing personal choices and traits of the respondents, besides demanding a specific and lifelong routine care. It is concluded that bothers and sisters of individuals with autism need support to cope with it. Psychology can contribute to expand family support groups and services, especially in terms of the sibling's perspective.
\end{abstract}

Keywords: Sibling relations; Family relations; Autistic disorder.

V.T.

1 Prefeitura Municipal de Santa Maria, Secretaria de Município da Saúde. Av. Nossa Senhora Medianeira, 355, 97060-001, Santa Maria, RS, Brasil. Correspondência para/Correspondence to: P.K. CEZAR. E-mail: <pamelakurtz@gmail.com>.

2 Centro Universitário Franciscano, Centro de Ciências Humanas, Curso de Graduação em Psicologia. Santa Maria, RS, Brasil. 
Atualmente, o autismo está em evidência em âmbito nacional, tornando-se temática para políticas públicas na área da saúde e da educação. Em 2012, foi sancionada a Lei $n^{\circ} 12.764$ que instituiu a Política Nacional de Proteção dos Direitos da Pessoa com Transtorno do Espectro Autista (Brasil, 2012) e, em 2013, o Ministério da Saúde lançou as Diretrizes de Atenção à Reabilitação da Pessoa com Transtornos do Espectro do Autismo (Brasil, 2013).

Contudo, embora o autismo tenha ocupado lugar privilegiado no cenário contemporâneo, suas causas e modalidades de intervenção permanecem transitando entre o orgânico, o ambiental e o psíquico (Jerusalinsky, 2013). Portanto, é possível encontrar diferentes etiologias e níveis de gravidade desse diagnóstico e, por isso, é importante compreender o autismo como um quadro clínico de início precoce que compromete o processo de desenvolvimento humano, especialmente nos âmbitos da comunicação e da interação social (Facion, Marinho, \& Rabelo, 2002; Goergen, 2013; Klin \& Mercadante, 2006; Schimidt, Dell'Aglio, \& Bosa, 2007).

Além disso, é interessante destacar que estudos atuais têm apresentado e discutido avanços de base neurobiológica na compreensão do autismo (Garcias, 2013; Tuchman \& Rapin, 2009). Ressalta-se ainda que o diagnóstico em questão é marcado, sobretudo, pela incapacidade de estabelecer um sistema adequado de comunicações com o ambiente social. Essas dificuldades podem ocorrer não só devido ao atraso na aquisição da linguagem e ao uso estereotipado e repetitivo da fala, mas também em decorrência da falta de reciprocidade social e emocional que o autista apresenta em suas relações (Facion et al., 2002; Marcelli, 1998; Schimidt et al., 2007). Destaca-se que tais características são perceptíveis desde muito cedo, sendo mais evidentes por volta do primeiro e segundo anos da criança (Marcelli, 1998; Smeha \& Cezar, 2011), entretanto é possível observar sinais indicativos de autismo em bebês ainda mais jovens (Jerusalinsky et al., 2013; Lampreia, 2009).

Salienta-se que as dificuldades na comunicação e na interação social afetam inclusive as 52 pessoas mais próximas ao autista e que estão dire- tamente envolvidas em seus cuidados (Jerusalinsky et al., 2013; Semensato \& Bosa, 2013). Somada a essas dificuldades, as pessoas com autismo também se deparam com limitações na realização de atividades corriqueiras, como higiene e alimentação, as quais podem estar associadas aos comportamentos rígidos, agressivos ou repetitivos apresentados por eles. Em decorrência disso, a necessidade de cuidados diferenciados e a dependência dos pais e demais cuidadores é acentuada, levando a família a constantes mudanças na sua rotina a fim de se adaptar às características do familiar com autismo (Fávero \& Santos, 2005; Schmidt et al., 2007; Smeha \& Cezar, 2011).

Estas, em geral, são graves e persistentes, mas é necessário salientar que existem particularidades de cada autista e de cada dinâmica familiar (Fernandes, 2009). Desse modo, o impacto do diagnóstico nas famílias não pode ser desprezado (Fernandes, 2009; Sifuentes \& Bosa, 2010), pois essas características afetam os diversos membros da família nuclear e extensa. Assim, estudos têm se preocupado em investigar as repercussões do autismo na família, especialmente nos âmbitos da dinâmica familiar e da maternidade (Fávero \& Santos, 2005; Schmidt \& Bosa, 2004; Schmidt et al., 2007; Semensato \& Bosa, 2013; Smeha \& Cezar, 2011).

Por sua vez, pesquisas que apresentam os impactos do transtorno autístico nos irmãos, em geral, são de caráter quantitativo, comparativo e/ou bibliográfico, e discorrem, por exemplo, sobre a qualidade de vida dos irmãos de autistas, e/ou a qualidade das relações familiares, das interações sociais e da comunicação (Araújo, Souza-Silva, \& D’Antino, 2012; Gomes \& Bosa, 2004; Marciano, 2007; Pais, 2012; Smith \& Elder, 2010; Vieira \& Fernandes, 2013; Yirmiya et al., 2006). Além disso, também já se pesquisou a respeito do risco de autismo em bebês irmãos de autistas (Lampreia, 2009) e rastreamento de sinais e sintomas do diagnóstico em irmãos (Mecca et al., 2011). No entanto ainda são insuficientes os estudos qualitativos que investigam o impacto do transtorno autístico no subsistema fraterno na perspectiva de irmãos adultos, com intuito de compreender as vivências e significados atribuídos por esses sujeitos em relação 
ao autismo do irmão e às repercussões em suas vidas.

Por outro lado, os estudos sobre a relação fraterna entre irmãos com desenvolvimento típico também são insuficientes, dada a complexidade dessa relação, e quando realizados tendem a focalizar questões como competição, ciúme e/ou rivalidade (Goldsmid \& Féres-Carneiro, 2011). O que não pode ser desconsiderado é o fato de que a relação entre irmãos interfere na dinâmica familiar. Uma vez que é na família, em especial, por meio das relações entre pais e irmãos, que ocorrem as primeiras aprendizagens, o processo de socialização e consequentemente o desenvolvimento da personalidade (Fernandes, Alarcão, \& Raposo, 2007). Nesse sentido, as relações fraternas são fundamentais na vida do sujeito, influenciando na estruturação da vida psíquica individual e também da social (Goldsmid \& Féres-Carneiro, 2011).

Ao considerar a hierarquia familiar, constata-se que os irmãos pertencem ao mesmo subsistema e estabelecem uma relação mais igualitária e duradoura (Muniz \& Carneiro, 2012). Nesta, o vínculo fraterno pode se tornar um dos laços mais ricos e contínuos, já que pode durar da infância até a velhice do sujeito (Oliveira, 2006; Núñez, Rodrígues, \& Lanciano, 2007). Assim, as interações entre irmãos são permeadas por inúmeros sentimentos: rivalidade, competição, ciúmes, carinho, lealdade, companheirismo, os quais são, por vezes, ambivalentes. Por isso, podem ser pensadas como um laboratório de relações sociais, sendo modelo para as futuras e demais interações realizadas para além do sistema familiar (Oliveira, 2006; Silveira, 2002).

Por conseguinte, após refletir acerca dos impactos do autismo na família e da importância e influência da relação fraterna para a dinâmica familiar, individual e social do sujeito, o objetivo principal, neste estudo, foi compreender a repercussão de ter um irmão com autismo na trajetória de vida de sujeitos adultos. Para tanto escutou-se a história singular de irmãos de autistas, resgatando a experiência da relação fraterna, os sentimentos que perpassam tal vivência, a rotina de cuidados, a relação com a família nuclear e extensa e as perspectivas futuras dos participantes.

\section{Método}

\section{Instrumentos}

Nesta pesquisa a abordagem é qualitativa com delineamento exploratório e transversal. Como instrumentos para coleta de dados, utilizaram-se entrevistas semiestruturadas, as quais seguiram um roteiro com temas norteadores (percepções sobre a relação fraterna; sentimentos; rotina de cuidados; repercussões do autismo na família e relações sociais; influências nas escolhas e modo de ser; perspectivas futuras). As entrevistas foram realizadas individualmente, em locais escolhidos pelos participantes, com duração aproximada de uma hora e gravadas em áudio.

\section{Participantes}

Os critérios de inclusão para participar do estudo foram: idade superior a 18 anos e ter um irmão com diagnóstico de autismo que não tivesse outra condição clínica ou doença associada. A escolha dos participantes ocorreu por meio de indicações. Além disso, também foram contatadas seis instituições (de saúde, educação e/ou Organizações Não Governamentais [ONG], sendo quatro públicas e duas privadas) que atendem a pessoas com autismo, em uma cidade de médio porte do interior do Rio Grande do Sul.

A composição final dos participantes foi de quatro irmãos adultos, os quais serão apresentados pelas denominações P1, P2, P3 e P4:

- P1: 19 anos, sexo masculino, solteiro, ensino superior incompleto, sem filhos, tem duas irmãs (18 e seis anos), ambas autistas;

- P2: 33 anos, sexo masculino, solteiro, com ensino superior, sem filhos, tem um irmão autista (24 anos) e outra irmã de 35 anos;

- P3: 33 anos, sexo masculino, solteiro, com ensino superior, sem filhos, tem uma irmã autista (31 anos), um irmão com síndrome de asperger (24 anos) e outra irmã de 13 anos;

- P4: 39 anos, sexo feminino, casada, com ensino médio incompleto, com uma filha de 15 anos e um irmão autista (26 anos). 


\section{Procedimentos}

Os dados coletados com as entrevistas foram analisados conforme a Análise Textual Qualitativa de Moraes (2003), também descrita como análise textual discursiva. Esse tipo de análise é empregado em pesquisas qualitativas, pois possibilita a compreensão do fenômeno investigado de maneira aprofundada. Desse modo, a análise textual permite a produção de um novo material, coletado por meio de entrevistas e/ou observações, onde os textos são construídos a partir dos discursos. Esse método é considerado um processo auto-organizado de construção de novas compreensões, decorrentes de uma sequência de procedimentos.

O processo de análise se inicia a partir de um conjunto de textos (discursos) válidos e confiáveis sobre o tema, denominado corpus da análise. Posteriormente, surgem as etapas de unitarização, categorização e comunicação. A primeira refere-se à desmontagem dos textos, que são examinados em detalhes para construir as unidades de análise. A etapa de categorização diz respeito ao estabelecimento das relações entre as unidades com intuito de constituir as categorias de análise e, por fim, ocorre o processo de comunicação, no qual acontece a compreensão renovada e ressignificada dos fenômenos. Então, após a análise das entrevistas, foram construídas três categorias: Vivências da relação fraterna; Repercussões do autismo e a família como suporte social/rede de apoio; Expectativas atuais e em relação ao futuro.

A pesquisa foi encaminhada para um Comitê de Ética em Pesquisa. Ela foi aprovada sob o número CAAE (Certificado de Apresentação para Apreciação Ética): 11238512.8.0000.5306, referentemente ao Parecer $n^{\circ} 177.385$ na data de 18 de dezembro de 2012

\section{Resultados e Discussão}

\section{Vivências da relação fraterna}

Em relação ao diagnóstico, foi possível com54 preender que a percepção do entrevistado de pos- síveis sinais de autismo no irmão variou conforme a diferença de idade entre ambos. Nos participantes em que essa diferença era maior, sendo o entrevistado o mais velho, estes relataram que conseguiam perceber com mais clareza certos indicativos, como visualizar que o irmão não estava se desenvolvendo de acordo com o esperado para a idade. Já os irmãos com idades mais próximas também referem que identificavam certos sinais, em especial no comportamento dos pais, os quais tendiam a tratar o outro irmão de forma diferenciada. A fala a seguir elucida tal situação:

Eu sabia que ela era diferente, mas não sabia o que era, eu notava que de vez em quando eles tratavam ela diferente, ... eu não lembro direito, devia ter uns dois ou três anos, que meus pais começaram a se preocupar quando ela demorô pra fala (P1).

Verifica-se, assim, que não são apenas os pais ou outros adultos que percebem as características do autismo, pois os irmãos, mesmo quando crianças ou adolescentes, também conseguiam identificar alguns sinais. Tal fato foi igualmente encontrado e destacado no estudo de Pietsrzak e Facion (2004).

Percebe-se, por meio da fala dos irmãos, que a confirmação do diagnóstico de autismo ocorreu de forma tardia, por volta dos cinco ou seis anos de idade. Os participantes atribuem tal situação ao pouco esclarecimento que havia na época e percebem que atualmente existe maior divulgação e possibilidades de tratamento. Ao encontro disso, identifica-se um maior investimento em políticas públicas voltadas ao autismo (Brasil, 2012, 2013), além do aumento na produção científica sobre o tema nos últimos anos (Fernandes, 2009; Teixeira et al., 2010) e a ênfase no diagnóstico precoce (Brasil, 2013; Jerusalinsky et al., 2013; Lampreia, 2009).

No que se refere aos sentimentos mobilizados pela vivência de ter um irmão com autismo, verificou-se, na fala dos entrevistados, a preocupação dos pais em tentar equilibrar a atenção aos filhos. Os participantes demonstraram que tinham consciência de que os cuidados seriam diferenciados, mas disseram que tentaram entender a 
situação sem sentir ciúmes ou raiva do irmão. Os sentimentos relatados foram de carinho pelo irmão autista, companheirismo associado à família, vontade de cuidar do irmão e ajudar os pais e, também, sentimentos de preocupação e angústia, demonstrando que tal vivência é difícil e complexa, conforme relatado na fala:

É assim ó, eu gosta dessa situação eu não gosto. Mas ninguém tem culpa né... . Mas ela nunca assim, em relação a isso, nunca ela deixo a deseja, porque eu sempre soube entende isso, da dedicação a mais pra ele né (P4).

Por outro lado, embora a relação entre irmãos com desenvolvimento típico seja marcada pela ambivalência de sentimentos (Silveira, 2002), como rivalidade, ciúmes, lealdade e cooperação (Oliveira, 2006), no caso da relação fraterna no contexto do autismo, essa ambivalência parece se amenizar, uma vez que os irmãos parecem estar mais engajados com a necessidade de cuidar daquele com transtorno autístico do que de interagir e/ou competir com ele. Os participantes percebem essa diferenciação na relação fraterna, pois o irmão autista, em alguns momentos, passou a ser visto mais como um filho. A fala a seguir elucida tal situação: "o Xé irmão, mas aquela coisa, filho-irmão, porque a gente tem que te um cuidado a mais com ele... aquela coisa de te convivido com ele, mas não como irmão normal, mais de filho mesmo" (P4). Destaca-se que essa inversão de papéis pode ocorrer justamente devido às mudanças no contexto familiar para se adaptar às novas necessidades do familiar com limitações (Araújo et al., 2012; Pais, 2012).

Quanto às percepções da relação fraterna, é no âmbito das interações e brincadeiras que começam a se tornar mais evidentes as diferenças e particularidades da relação entre irmãos quando um deles tem autismo. No contexto do desenvolvimento típico a relação fraterna torna-se um laboratório de relações sociais (Oliveira, 2006; Silveira, 2002), um espaço de socialização, caracterizado por interação, trocas e aprendizagem (Fernandes et al., 2007; Muniz \& Carneiro, 2012). Contudo, no contexto do autismo, percebe-se que tais interações são prejudicadas e nem sempre ocorrem como o esperado. Esse fato também foi encontrado no estudo de Pais (2012). Nos relatos dos participantes, percebeu-se que sempre existiram tentativas de interagir e de brincar com o irmão autista, mas, conforme a severidade do quadro, isso se tornava mais difícil, como exemplificado no relato a seguir:

Ele não interagia muito, brincava com os brinquedos dele, não se socializava com as pessoas, então pra ele o mundo girava em torno dos brinquedos que ele tinha, dos movimentos repetitivos que ele tinha, ele não tinha a dependência de buscar outros, buscava e ele não reagia... (P2).

Outro ponto que diferencia esse tipo de relação fraterna em comparação com a relação entre irmãos com desenvolvimento típico refere-se à rotina de cuidados. É comum que os irmãos ajudem os pais nas tarefas diárias da casa ou nos cuidados com irmãos menores, todavia, quando um familiar possui autismo, toda a dinâmica familiar passa por modificações. Em decorrência disso, os irmãos de autistas se envolvem diretamente na rotina de cuidados, sendo que tal envolvimento começa na infância, passa pela adolescência e segue na vida adulta. Essa participação mais ativa também é referida nos estudos de Araújo et al. (2012), Gomes e Bosa (2004), Pais (2012) e Pietsrzak e Facion (2004).

No caso dos participantes deste estudo, os mesmos relataram que os cuidados com o irmão autista referem-se a atividades mais básicas, como alimentação, higiene, cuidar do irmão em casa enquanto os pais estão fora, levar à escola ou a alguma consulta médica, psicológica, entre outras. Contudo, a sobrecarga de tarefas segue sendo dos pais, em especial da mãe, sendo que os participantes reportam bastante preocupação com relação a isso e, portanto, fazem o possível para ajudar, na tentativa de minimizar essa intensa rotina de cuidados. Assim, conforme Araújo et al. (2012), é comum que os irmãos se envolvam diretamente nos cuidados do irmão autista, justamente em uma tentativa de amenizar a sobrecarga de cuidados da mãe.

Por conseguinte, os irmãos acabam precisando renunciar a alguns aspectos de sua vida particular, como deixar de sair com amigos, mudar al- 
guns horários de trabalho, passar mais tempo em casa, entre outros. Isso pode ser observado na fala: "sempre tentei ajuda no que podia, mesmo sendo uma criança, tentava dá força, praticamente ajudei a criar ela ... cuidava das gurias, pra elas não ficarem sozinhas em casa, já deixei de sai com amigos pra fica com elas" (P1).

As vivências da relação fraterna, no contexto do autismo, trazem questões que são específicas dessa relação, como por exemplo, no âmbito das interações e rotina de cuidados. Em decorrência disso, percebe-se que tais experiências influenciaram nas escolhas e no modo de ser dos participantes.

Essas influências perpassam desde a escolha profissional até algumas atitudes pessoais, a saber, os participantes se consideram mais maduros e responsáveis, sentem a necessidade de serem fortes perante os pais, afirmam não terem sido rebeldes em suas adolescências, justamente para não trazer mais preocupação, uma vez que entendiam que o autismo do irmão já era preocupação suficiente para os pais. Esse sentimento de maturidade e responsabilidade também é evidenciado no estudo de Pietsrzak e Facion (2004). A fala a seguir ilustra o quanto o autismo do irmão está atrelado às escolhas pessoais e ao modo de ser do participante:

Elas influenciam bastante... ser maduro né, eu tinha que fica firme pra ajuda meus pais sabe... inclusive eu vim pra cá pra estuda, pra não ser mais um empecilho pra eles, eu quero luta pra paga a faculdade, pra não ter que dependê deles, pra eles poderem se concentrá nas gurias... que as meninas são autistas, as duas, eu tinha que investigá porque... e ai até uma das coisas que me levou a Psicologia sabe (P1). fraterna é afetada no contexto do autismo e os irmãos com desenvolvimento típico se deparam com situações que mobilizam inúmeros sentimentos, os quais influenciam em seus comportamentos e escolhas pessoais. Contudo, para além do núcleo familiar, tal situação repercute na família extensa e

\section{Repercussões do autismo e a família como suporte social/rede de apoio}

Em relação às repercussões do diagnóstico de autismo na família, foi possível encontrar experiências distintas em consonância com os relatos dos participantes do estudo. Algumas falas apontam que, embora tenha sido uma experiência difícil, o autismo do irmão foi também motivo de fortalecimento dos vínculos familiares. Por outro lado, houve relatos os quais salientavam que a família extensa não aceitou bem o diagnóstico e manteve-se distante da família nuclear.

Quanto às repercussões nas relações sociais, os participantes também citam situações que perpassam experiências de aceitação e estranhamento. Os entrevistados relataram que, após o diagnóstico de autismo, a família deixou de frequentar certos espaços públicos em muitas situações e até mesmo se afastou de alguns familiares, fosse por medo, por insegurança em relação ao comportamento do autista, fosse por perceber preconceitos e pouca aceitação social da condição.

Ao encontro disso, o estudo de Smeha e Cezar (2011) indica que o preconceito está presente no contexto do transtorno autístico e gera sentimentos de tristeza, indignação e vontade de proteger ainda mais o familiar autista, visto muitas vezes como indefeso. Nesse aspecto, os participantes relataram diversos momentos difíceis e delicados que fizeram parte de trajetória de vida com o irmão. Na fala a seguir, é possível visualizar uma dessas situações:

Foi num carnaval, minha irmã tava na rua com uma amiguinha, a gente tava perto de olho, veio um cara bêbedo e deu um selinho nela... meus pais me seguraram, fiquei muito brabo, por que eles não fazem ideia do que a gente passa pra cuida delas (P1).

Em relação ao apoio familiar nesse contexto, percebe-se que quanto maior o apoio da família extensa menos sobrecarregada fica a família nuclear, pois existe um compartilhamento de responsabilidades que aparece como solidariedade entre os membros. Nesse sentido, o suporte social dos parentes tem sido apontado como importante fator 
de apoio às famílias de autistas (Fávero \& Santos, 2005; Smeha \& Cezar, 2011).

Por outro lado, quando esse apoio não ocorre, existe um afastamento da família extensa e, consequentemente, uma sensação de desamparo, porque a rede de apoio fica reduzida à família nuclear. Esta, em alguns casos, resume-se à mãe e ao filho sem autismo, uma vez que nem sempre o pai é presente nos cuidados diários, como esclarece a fala a seguir:

A gente na verdade não pode contar com ninguém. Na família mesmo, aparecem no aniversário dele alguns, e não passa disso. E a gente é a gente mesmo... eu tenho sentido que a mãe tá bem sobrecarregada, porque se ela tivesse o apoio dele, meu pai no caso, claro que não iria resolvê a situação, mas como iria melhora né (P4).

Portanto, percebe-se que os filhos com desenvolvimento típico que participaram deste estudo são referência para os pais desde muito cedo em suas vidas e, em alguns casos, tornam-se a principal rede de apoio no que se refere aos cuidados com o irmão autista. Portanto, o sentimento de responsabilidade é acentuado, pois os irmãos entendem que precisam ajudar os pais para que não fiquem sobrecarregados. Por sua vez, essa preocupação em relação aos cuidados com o irmão autista segue na vida adulta dos participantes.

\section{Expectativas atuais e em relação ao futuro}

Essa categoria apresenta os desejos e planos pessoais dos participantes e também os desejos e planos em relação ao irmão autista. Assim, no que se refere aos pessoais, foi perceptível, por meio das falas dos irmãos, o desejo pela independência. Logo, embora saibam que precisam continuar ajudando os pais, também entendem que é necessário seguir em frente e olhar para suas necessidades particulares.

As falas a seguir demonstram tal situação:

Eu queria ajudá meus pais, gostava de ajudá eles, só que eu não podia me prendê por isso sabe. Não queria ficá preso por isso.
Então outro motivo pra vir pra cá, pra tê essa liberdade sabe (P1).

Eu acho que comecei a procurar um pouco da minha independência também, então busquei um espaço, comprei um apartamento, e muito próximo ao deles, não fiz nada longe deles (P2).

Outro fator a ser destacado refere-se a ter filhos. Os três participantes que ainda não os têm relatam esse desejo, mas também expressam sentimentos de medo e preocupação, pois fazem alguma relação entre o autismo do irmão e a chance de nascer-lhes um filho com o mesmo diagnóstico. Isso pode ser exemplificado nas falas abaixo:

Penso em ter um, um pelo aspecto financeiro, e outro porque bate no fundo um medinho também de vim com problemas... não só eu, mas a mãe também tem essa preocupação, mas eu tento não pensá muito nisso, se acontecê, aconteceu, questão é que eu quero ter um filho (P3).

Eu pensei bastante já, tô ciente de que tem um grande risco de meus filhos poderem ser autistas, mas já conversei com minha namorada sobre isso... ir no geneticista antes de ter filhos, pra ver as probabilidades de isso acontecê, mas se acontecê eu vou tá preparado sabe, não vai sê o fim do mundo (P1).

Nos desejos e planos em relação ao irmão autista, especificamente em no que diz respeito aos tratamentos, percebe-se que a idade do irmão e o grau de severidade do diagnóstico influenciam nas expectativas de melhora. Quanto mais velho o irmão com transtorno autístico e quanto maior a gravidade do diagnóstico, menor é a expectativa, uma vez que a trajetória por tratamentos foi extensa e os participantes entendem que o quadro não irá se alterar de maneira significativa, esperando apenas por pequenas melhoras nas atividades diárias, como maior autonomia em questões de higiene ou alimentação.

Por outro lado, em relação ao futuro, os participantes do estudo demonstram saber que, diante da morte de seus pais, serão eles a assumir os 
cuidados do autista. No entanto, essa atribuição torna-se menos difícil quando existe outro irmão para compartilhar essas responsabilidades. Nos estudos de Gomes e Bosa (2004) e Pietsrzak e Facion (2004) há referência de que os irmãos de autistas possuem sentimentos de medo e insegurança em relação ao futuro. Portanto, falar sobre o futuro nessa perspectiva é algo que mobiliza angústia, fazendo com que prefiram viver o presente. Isso pode ser constatado nos relatos a seguir:

Às vezes eu tento pensá, mas às vezes eu prefiro esperar, e deixá que aconteça, porque senão tu fica pensando e não adianta ficá pensando agora, é esperar e o que tiver que resolver no futuro resolve. Então é esse o pensamento sobre o futuro que eu tenho. Que nós temos responsabilidades eu sei que eu tenho, já tô tendo agora (P3).

Entretanto, mesmo preferindo pensar no presente os participantes do estudo compreendem que a relação fraterna e familiar foi influenciada pelo autismo do irmão. Essas percepções ocorreram desde a infância e acompanharam suas trajetórias a ponto de saberem que, independentemente do que aconteça, por serem irmãos de um autista terão que assumir outras responsabilidades para além de seus planos individuais. Pode-se verificar isso na fala a seguir: "É tem certas coisas que a gente vai... são coisas que vai pro resto da vida, tem que ajudá" (P3). Nesse aspecto, vê-se que o sentimento de independência é limitado, uma vez que suas vidas já estão, em certa medida, marcadas pelo autismo do irmão.

Salienta-se, portanto, que o impacto de ter um irmão com autismo não pode ser desprezado, tendo em vista as diversas repercussões que tal vivência pode acarretar na vida pessoal e social desses sujeitos. Assim, entende-se que a relação fraterna aqui investigada foi afetada pelo autismo, em especial no âmbito das interações fraternas e modificações na rotina familiar e individual dos participantes.

Os estudos que investigam a qualidade de vida de irmãos de autistas também apresentam que a relação fraterna é afetada de alguma maneira.

58 No entanto, destacam que o diagnóstico não pode ser considerado o fator que prejudica a qualidade de vida dos irmãos, visto que a presença de um evento no contexto familiar não será, necessariamente, um preditor de estresse para os membros do mesmo. Assim é preciso que exista uma compreensão ampliada sobre a rotina/dinâmica familiar, pois a qualidade de vida dos autistas, dos irmãos e das famílias é perpassada por uma multiplicidade de fatores (Araújo et al., 2012; Gomes \& Bosa, 2004; Marciano, 2007; Pais, 2012; Vieira \& Fernandes, 2013).

Por conseguinte, por meio deste estudo foi possível identificar que a repercussão de se ter um irmão com autismo é uma vivência complexa a qual não pode ser compreendida apenas como uma situação adversa, prejudicial, ou estressante. Isso porque a qualidade das relações no sistema familiar, o suporte social e a qualidade da assistência recebida podem minimizar os efeitos negativos e potencializar aspectos como a iniciativa, a responsabilidade e a capacidade de apoio recíproco (Gomes \& Bosa, 2004; Semensato e Bosa, 2013; Vieira \& Fernandes, 2013).

Destaca-se que, nesta pesquisa, buscou-se compreender as especificidades da relação fraterna no contexto do autismo, no entanto tais vivências não podem ser generalizadas, tendo em vista que cada dinâmica familiar possui características próprias, assim como cada autista e cada irmão de autista têm suas particularidades. É importante salientar que este estudo oportunizou um olhar singular para os irmãos, dando-lhes voz e tornando mais visível essa vivência tão peculiar e, com isso, possibilitando um olhar ampliado sobre o autismo e a relação fraterna.

Conclui-se que os irmãos de autistas também precisam de apoio e espaços de escuta para que possam compartilhar suas experiências, angústias, incertezas e até mesmo dar novos significados para essa vivência. Nesse sentido, destaca-se a importância de intervenções da Psicologia e demais profissões da área da saúde por meio de orientações, grupos de apoio aos irmãos de autistas, intervenções individuais e familiares, entre outras, tendo em vista que, apesar de o autista ser o foco dos atendimentos, os demais familiares também 
necessitam de suporte e cuidado. É importante destacar que essas intervenções sejam dinâmicas e interdisciplinares e que estejam em consonância com a realidade das famílias (Gomes \& Bosa, 2004; Harris, 2001; Pais, 2012).

Ressalta-se, nesse aspecto, que as políticas públicas voltadas para o autismo nem sempre conseguem acolher as famílias em suas necessidades singulares, focando, na maioria das vezes, no tratamento e no familiar autista. Portanto, entende-se que a Psicologia pode, também, auxiliar na ampliação da rede de apoio às famílias, em especial na escuta desses irmãos, os quais também estão diretamente envolvidos. Outra contribuição da área refere-se a possibilidade de mediação, onde o psicólogo pode promover a melhor comunicação da família com a equipe de saúde.

Por fim, destacam-se algumas limitações do estudo, o qual apresenta uma amostra pequena de participantes por conta dos critérios de inclusão. Os autistas que frequentavam as instituições contatadas, em geral, não tinham irmãos ou estes tinham menos de 18 anos de idade. Houve situações em que existiam irmãos mais velhos, mas o autista tinha outra condição clínica como surdez ou síndrome de Down. Salienta-se, também, a dificuldade em encontrar participantes do sexo feminino para o estudo.

Desse modo, não foi possível, por exemplo, visualizar se existe especificidade nas percepções da vivência fraterna para homens ou para mulheres. Por outro lado, tais limitações podem ser consideradas como propostas para futuras pesquisas qualitativas, uma vez que a relação entre irmãos ainda é pouco explorada no âmbito científico, em especial, no contexto do autismo.

\section{Colaboradores}

Todos os autores contribuíram na concepção e desenho do estudo, análise de dados e redação final do artigo.

\section{Referências}

Araújo, R. R., Souza-Silva, J. R., \& D’Antino, M. E. F. (2012). Breve discussão sobre o impacto de se ter um irmão com transtorno do espectro do autismo. Cadernos de Pós-Graduação em Distúrbios do Desenvolvimento, 12(1), 9-15.

Brasil. Ministério da Saúde. (2013). Diretrizes de atenção à reabilitação da pessoa com transtornos do espectro do autismo. Brasília: Autor.

Brasil. Presidência da República. (2012). Lei nº 12.764, de 27 de dezembro de 2012. Institui a Política Nacional de Proteção dos Direitos da Pessoa com Transtorno do Espectro Autista. Brasília: Casa Civil. Recuperado em janeiro 4, 2014, de http://www. planalto.gov.br/ccivil_03/_ato2011-2014/2012/lei/ 112764.htm

Facion, J. R., Marinho, V., \& Rabelo, L. (2002). Transtorno autista. In J. R. Facion (Org.), Transtornos invasivos do desenvolvimento associados a graves problemas do comportamento: reflexões sobre um modelo integrativo (pp.23-38). Brasília: CORDE.

Fávero, M. A. B., \& Santos, M. A. (2005). Autismo infantil e estresse familiar: uma revisão sistemática da literatura. Psicologia: Reflexão e Crítica, 18(3), 358-369.

Fernandes, F. D. M. (2009). Famílias com crianças autistas na literatura internacional. Revista da Sociedade Brasileira de Fonoaudiologia, 14(3), 427-432.

Fernandes, O. M., Alarcão, M., \& Raposo, J. V. (2007). Posição na fratria e personalidade. Estudos de Psicologia (Campinas), 24(3), 297-304. http://dx.doi.org/ 10.1590/50103-166X2007000300001

Garcias, G. L. (2013). Genética do autismo. In C. Schmidt (Org.), Autismo, educação e transdisciplinariedade (pp.61-80). Campinas: Papirus.

Goergen, M. S. (2013). Sobre o diagnóstico em Transtorno do Espectro do Autismo (TEA): considerações introdutórias à temática. In C. Schmidt (Org.), Autismo, educação e transdisciplinariedade (pp.29-41). Campinas: Papirus.

Goldsmid, R., \& Féres-Carneiro, T. (2011). Relação fraterna: constituição do sujeito e formação do laço social. Psicologia USP, 22(4), 771-787.

Gomes, V. F., \& Bosa, C. A. (2004). Estresse e relações familiares na perspectiva de irmãos de indivíduos com transtornos globais do desenvolvimento. Estudos de Psicologia (Natal), 9(3), 553-561. http://dx.doi.org/10. 1590/S1413-294X2004000300018

Harris, S. L. (2001). Los hermanos de niños com autism: su rol especifico em las relaciones familiares. Madrid: Narcea.

Jerusalinsky, A. (2013). Editorial. Correio APPOA, 222/223, 1-3.

Jerusalinsky, J., Freire, A. B., Jerusalinsky, A., Mascarenhas, C., Teperman, D., Telles, H. P., \& Pimenta, P. (2013). Autismos e seus tratamentos: contribuições da metodologia psicanalítica nesse campo. Correio APPOA, 222/223, 25-45. 
Klin, A., \& Mercadante, M. T. (2006). Autismo e transtornos invasivos do desenvolvimento. Revista Brasileira de Psiquiatria, 28(Supl.1), 1-2.

Lampreia, C. (2009). Perspectivas da pesquisa prospectiva com bebês irmãos de autistas. Psicologia: Ciência e Profissão, 29(1), 160-171.

Marcelli, D. (1998). Psicoses infantis. In D. Marcelli. Manual de psicopatologia da infância de Ajuriaguerra (5 ed., pp.201-26). Porto Alegre: Artmed.

Marciano, A. R. F. (2007). Qualidade de vida de irmãos de portadores de autismo. In F. B. Assumpção Junior, \& E. Kuczynski. Autismo infantil: novas tendências e perspectivas. São Paulo: Atheneu.

Mecca, T. P., Bravo, R. B., Velloso, R. L., Schwartzman, J. S., Brunoni, D., \& Teixeira, M. C. T. V. (2011). Rastreamento de sinais e sintomas de transtornos do espectro do autismo em irmãos. Revista de Psiquiatria do Rio Grande do Sul, 33(2), 116-120.

Moraes, R. (2003). Uma tempestade de luz: a compreensão possibilitada pela análise textual qualitativa. Ciência e Educação, 9(2), 191-211.

Muniz, A. A., \& Carneiro, T. F. (2012). Função fraterna: reflexões a partir do filme Príncipe das Marés. Psicologia em Revista, 18(1), 41-56.

Núñez, A. B., Rodríguez, L., \& Lanciano, S. (2007). El vínculo fraterno cuando uno de los hermanos tiene discapacidad. In B. A. Núñez. Familia y discapacidad: de la vida cotidiana a la teoría (pp.225-56). Buenos Aires: Lugar.

Oliveira, A. L. (2006). Família e irmãos. In C. M. O. Cerveny (Org.), Familia e narrativas, gênero, parentalidade, irmãos, filhos nos divórcios, genealogia, história, violência, intervenção sistêmica, rede social (pp.63-81). São Paulo: Casa do Psicólogo.

Pais, I. D. B. (2012). Qualidade de vida dos irmãos de indivíduos com autismo (Dissertação de mestrado não-publicada). Universidade Católica Portuguesa, Viseu, Portugal. Recuperado em abril 25, 2014, de http://repositorio.ucp.pt/bitstream/10400.14/12505/ 1/Tese \%20In\%C3\%AAs.pdf

Pietsrzak, S. P., \& Facion, J. R. (2004). Pessoas com autismo e seus irmãos. Revista Intersaberes, 1(1), 168-185.

Schmidt, C., \& Bosa, C. A. (2004). A investigação do impacto do autismo na família: revisão crítica da literatura e proposta de um novo modelo. Interação, 7(2), 111-120.
Schmidt, C., Dell'Aglio, D. D., \& Bosa, C. A. (2007). Estratégias de coping de mães de portadores de autismo: lidando com as dificuldades e com a emoção. Psicologia: Reflexão e Crítica, 20(1), 124-131.

Semensato, M. R., \& Bosa, C. A. (2013). A família das crianças com autismo: contribuições empíricas e clínicas. In C. Schmidt (Org.), Autismo, educação e transdisciplinariedade (pp.81-103). Campinas: Papirus.

Sifuentes, M., \& Bosa, C. A. (2010). Criando pré-escolares com autismo: características e desafios da coparentalidade. Psicologia em Estudo, 15(3), 477-485.

Silveira, L. M. O. B. (2002). O relacionamento fraterno e suas características ao longo do ciclo vital da família. In A. Wagner (Org.), Família em cena: tramas, dramas e transformações (pp.93-112). Petrópolis: Vozes.

Smeha, L. N., \& Cezar, P. K. (2011). A vivência da maternidade de mães de crianças com autismo. Psicologia em Estudo, 16(1), 43-50.

Smith, L. O., \& Elder, J. H. (2010). Siblings and family environments of persons with autism spectrum disorder: A review of literature. Journal of Child and Adolescent Psychiatry Nursing, 23(3), 189-195.

Teixeira, M. C. T. V., Meca, T. P., Velloso, R. L., Bravo, R. B., Ribeiro, S. H. B., Mercadante, M. T., \& Paula, C. S. (2010). Literatura científica brasileira sobre transtornos do espectro autista. Revista da Associação Médica Brasileira, 56(5), 607-614.

Tuchman, R., \& Rapin, L. (2009). Autismo: abordagem neurobiológica. Porto Alegre: Artmed.

Vieira, C. B. M., \& Fernandes, F. D. M. (2013). Qualidade de vida em irmãos de crianças incluídas no espectro do autismo. CoDAS, 25(2), 120-127.

Yirmiya, N., Gamliel, T., Pilowsky, T., Feldman, R., BaronCohen, S., \& Sigman, M. (2006). The development of siblings of children with autism at 4 and 14 months: Social engagement, communication, and cognition. Journal of Child Psychology and Psychiatry, 47(5), 511-523.

Recebido: fevereiro 28, 2014

Versão final: maio 13, 2014

Aprovado: junho 9, 2014 